\title{
Juvenile osteochondritis of femoral condyles: treatment with transchondral drilling. Analysis of 40 cases
}

\author{
Rammal Hayan • Gicquel Phillipe • \\ Schneider Ludovic · Karger Claude • \\ Clavert Jean-Michel
}

Received: 6 October 2009/Accepted: 24 November 2009/Published online: 18 December 2009

(c) EPOS 2009

\begin{abstract}
Introduction Osteochondritis dissecans (OCD) of the femoral condyle is a rare lesion.

Materials and methods A retrospective study (level IV evidence) analyzing a series of 40 pediatric cases with juvenile femoral condyles osteochondritis treated by arthroscopic multiple transchondral drilling between February 1999 and June 2008 was undertaken. This lesion affected the medial condyle in $87.5 \%$ of cases. The average age at treatment was 13.4 years. Our study took into account the location of the lesion and its radiological evolutionary stage. The average follow up was 14.8 months. The postoperative evaluation was based on the clinical and radiological scores of Hughston.

Results Good clinical and radiological results in 97.5 and $95 \%$ of cases,respectively were obtained, with a significant correlation $(P<0.001)$ between clinical scores and radiological Hughston scores. The closed nature of the growth plate during surgery has a significant deleterious effect $(P<0.001)$ on the clinical and radiological score of Hughston.

Conclusion All patients presenting juvenile condylar osteochondritis with open growth plate during treatment had good clinical and radiological results, confirming the validity and effectiveness of multiple transchondral drilling in this type of lesion.
\end{abstract}

R. Hayan $(\varangle) \cdot$ G. Phillipe $\cdot$ S. Ludovic $\cdot$ K. Claude

C. Jean-Michel

Pediatric Orthopedic Surgery Department,

Hautepierre Hospital, Moliere Avenue,

67098 Strasbourg Cedex, France

e-mail: hayanmd@gmail.com
Keywords Juvenile osteochondritis dissecans . Femoral condyles - Arthroscopic transchondral drilling

\section{Introduction}

Osteochondritis dissecans (OCD), a term introduced by König in 1887 [1], is a rare lesion that affects the articular cartilage and the epiphyseal bone and may result in lack of consolidation to the separation of osteochondral fragment [2-6].

Most cases of OCD (75\%) are present at the knees and three-quarters of those occur in the medial femoral condyle [7].

The pathophysiology of this disease is still mysterious and several etiological hypotheses have been discussed [810]: repetitive microtrauma, ischemia, lack of ossification, genetic cause, etc.

Treatment is variable and depends on both the lesion itself (stable or unstable) and the patient (closure or nonclosure of the growth plate) $[2,7,8]$.

The objective of this study is to evaluate the results in the medium and long term of femoral condyles OCD in children and adolescents carried out by arthroscopic multiple transchondral drilling.

\section{Materials and methods}

Between February 1999 and June 2008, 39 patients with juvenile osteochondritis of femoral condyles (accounting for 40 cases) were treated by arthroscopic transchondral drilling. Among the patients, 28 (71.8\%) were male. The medial condyle was affected in $87.5 \%$ of cases, with involvement of the right knee in 14 cases, the left knee in 
Fig. 1 a Harding classification to distinguish anterior, mean, and posterior lesions. b Cahill and Berg classification for medio-lateral localization of the lesions
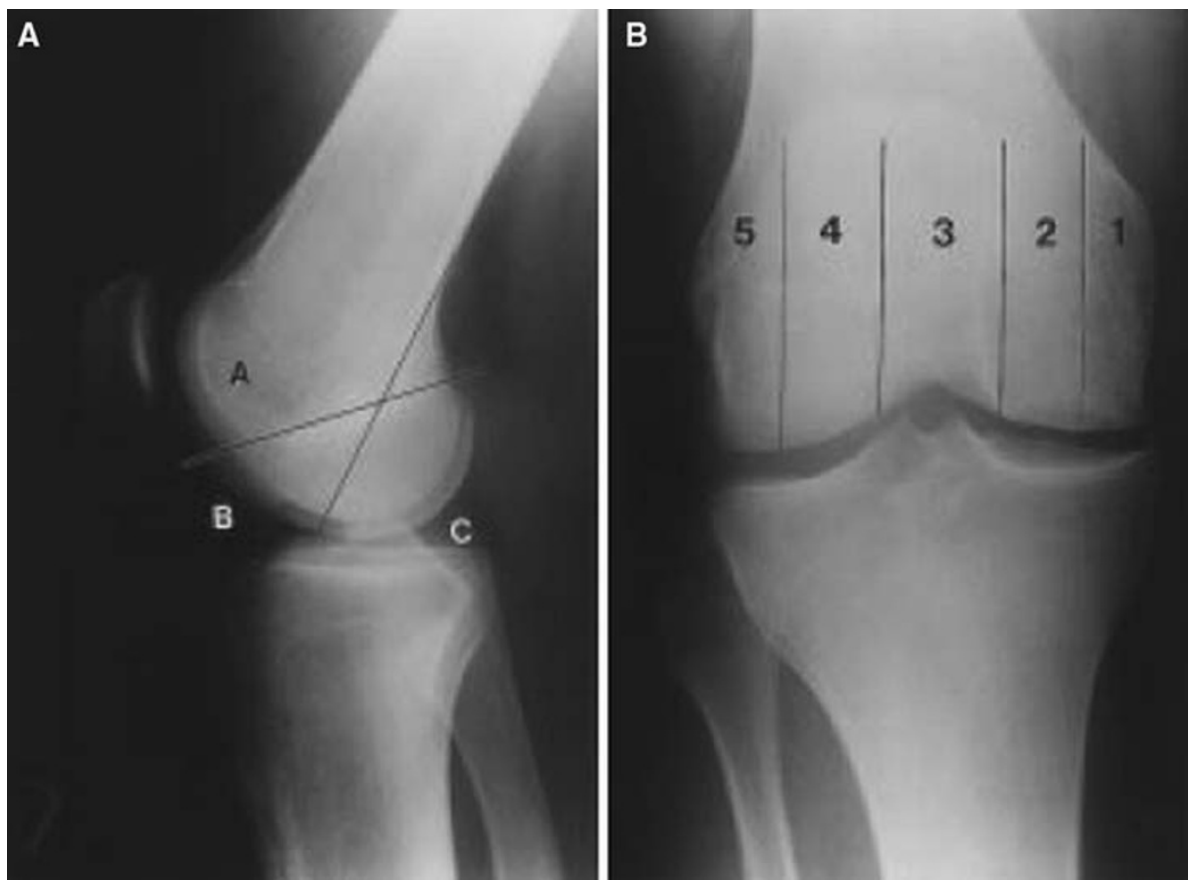

22 cases, and two cases of bilateral OCD. One patient had a unilateral bicondylar OCD. Among the five cases of OCD of the lateral condyle, two cases $(40 \%)$ were associated with discoid lateral meniscus.

The mean patient age at diagnosis of OCD was 12 years (range $8-16$ years). The average age at the time of surgery was 13.4 years, with age limits of 9.75 and 16.5 years.

Clinically, all patients complained of knee pain at diagnosis and one patient had episodes of locking associated with a discoid lateral meniscus.

Initially, all patients received conservative treatment by restriction of sports activities for an average of 6 months (range 3-12 months) without immobilization or nonweight-bearing gait.

A conventional radiography was performed in all patients (anteroposterior [AP], lateral, and skyline views). A computed tomography (CT) scan was performed in 15
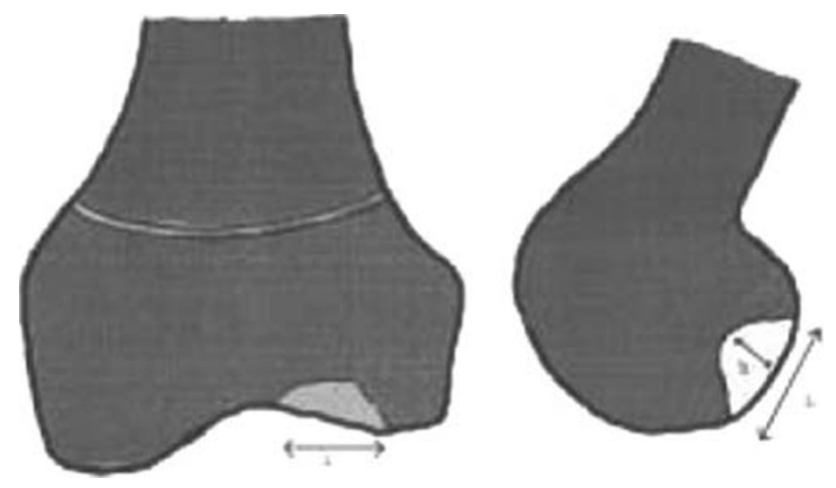

Fig. 2 Measures to calculate the lesion volume on anteroposterior (AP) and lateral views of the knee cases $(37.5 \%)$ and magnetic resonance imaging (MRI) in 21 patients $(52.5 \%)$.

Surgical indication was raised when symptoms persisted after conservative treatment was followed appropriately

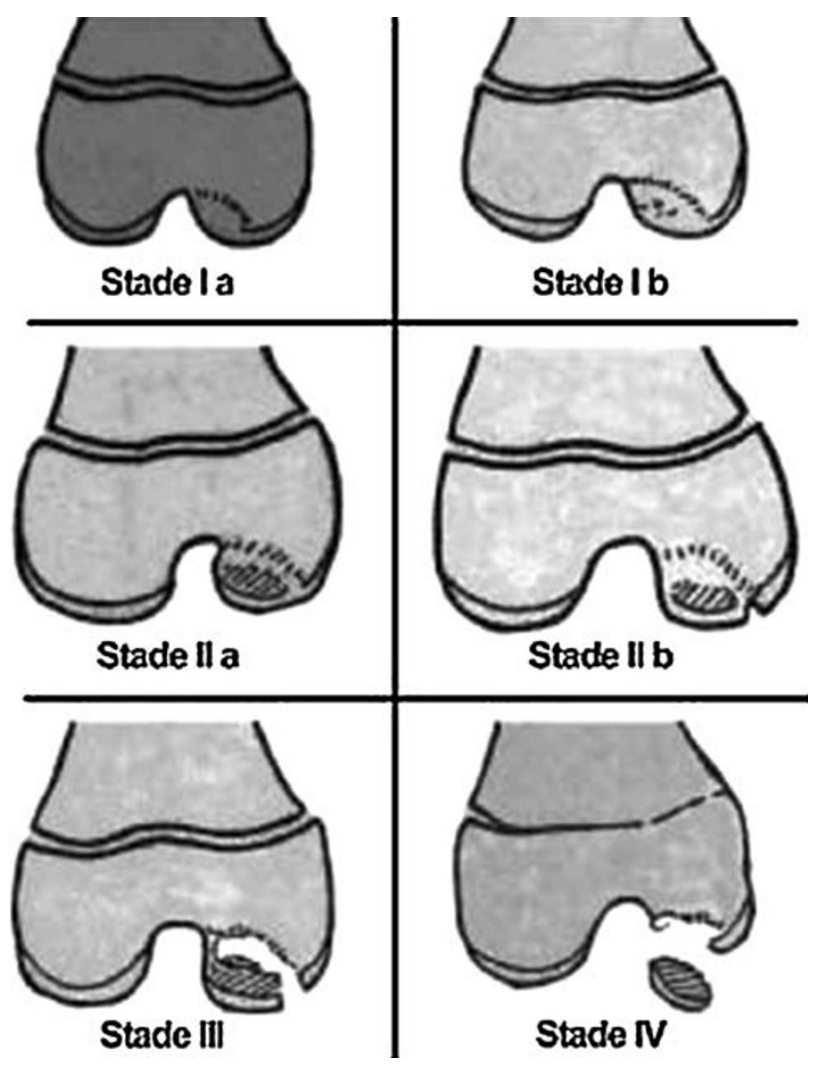

Fig. 3 Bedouelle's radiological classification 
and/or when the control radiographs showed a worsening of the lesion of osteochondritis, especially when approaching the end of growth.

The location of OCD was defined according to the classifications of Harding [11] and Cahill and Berg [3, 12] on the lateral and AP views, respectively (Fig. 1).

The radiographic evaluation, as classified by Cahill and Berg, showed a predominance of type 2 lesions $(87.5 \%)$ and, as classified by Harding, showed a predominance of type B lesions (85\%) against $12.5 \%$ of type C. One case had a lesion extended to areas $\mathrm{B}$ and $\mathrm{C}$ of the femoral condyle.

The volume of OCD lesions was measured on AP and lateral views (Fig. 2).

The mean volume of the lesions was $1,835.4 \mathrm{~mm}^{3}(204$ $6,750 \mathrm{~mm}^{3}$ ).
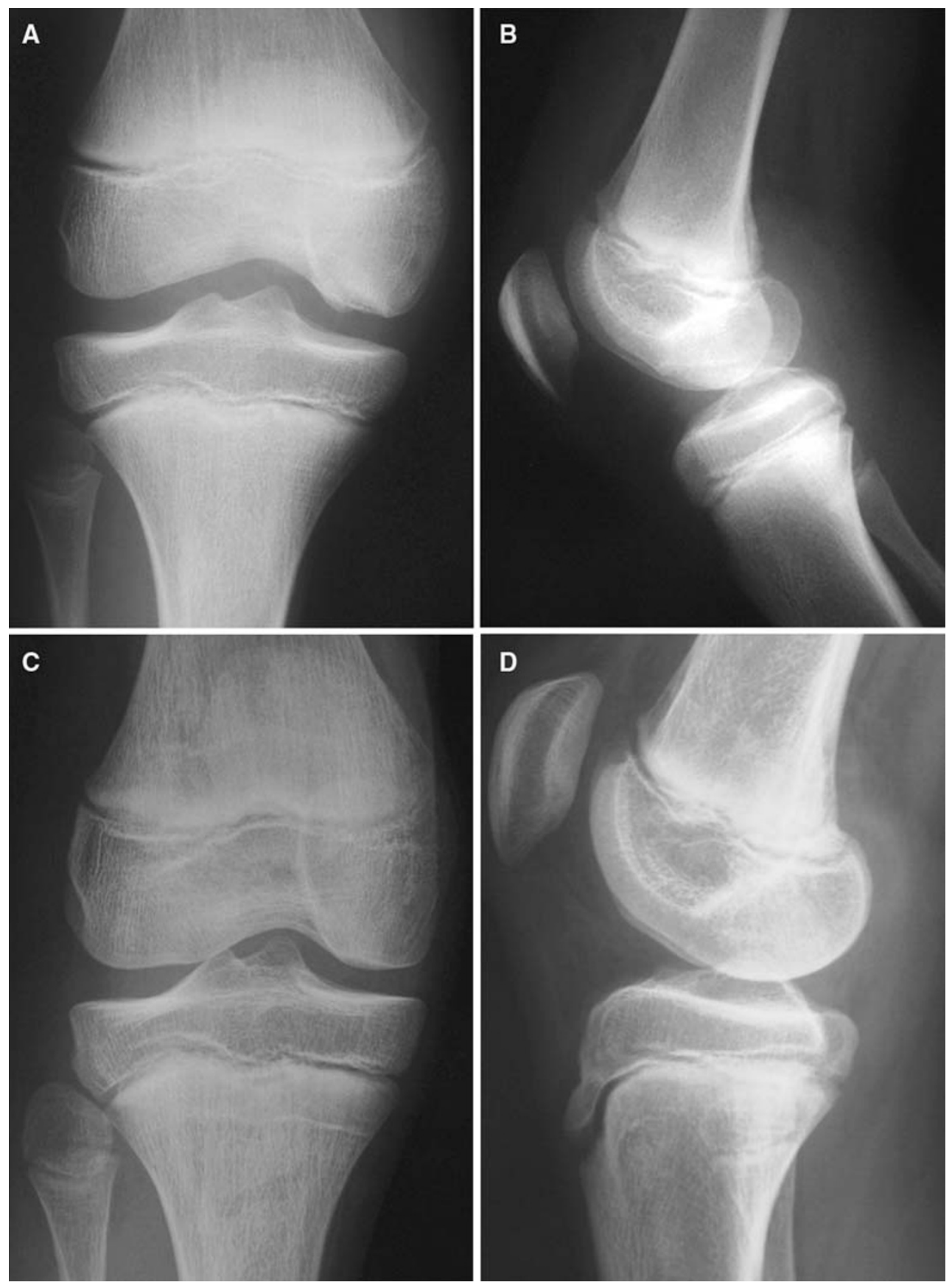

Fig. 4 a, b A patient with Cahill type 2, Harding type B, and Bedouelle grade IIb osteochondritis dissecans (OCD). c, d The same patient 19 months after a transchondral drilling with a Hughston radiological score of 4 
Table 1 Hughston clinical scale

\begin{tabular}{|c|c|c|}
\hline Excellent & 4 & $\begin{array}{l}\text { Normal sports activity } \\
\text { No symptoms } \\
\text { Normal physical examination }\end{array}$ \\
\hline Good & 3 & $\begin{array}{l}\text { Normal sports activity } \\
\text { Knee pain with intense activities } \\
\text { Normal physical examination }\end{array}$ \\
\hline Average & 2 & $\begin{array}{l}\text { Normal sports activity } \\
\text { Knee pain and swelling with intense activities } \\
\text { Normal physical examination }\end{array}$ \\
\hline $\mathrm{Bad}$ & 1 & $\begin{array}{l}\text { Knee pain and swelling with moderate activities } \\
\text { Flexum less than } 20^{\circ}\end{array}$ \\
\hline Failure & 0 & $\begin{array}{l}\text { Restriction of sports } \\
\text { Knee pain and swelling with daily activities } \\
\text { Flexum more than } 20^{\circ}\end{array}$ \\
\hline
\end{tabular}

Table 2 Hughston radiological scale

4 Normal

3 Defect or sclerosis

2 Flattening of the condyle

1 Irregular condyle with narrowing of the joint space less than $50 \%$

0 Knee arthritis with narrowing of the joint more than $50 \%$

The evolutionary stages of condylar osteochondritis were defined according to Bedouelle's classification [13] (Fig. 3).

The radiographic evaluation according to the classification of Bedouelle, at the time of surgery, noted $10 \%$ stage Ia, $15 \% \mathrm{Ib}, 40 \% \mathrm{IIa}, 22.5 \% \mathrm{IIb}$, and $12.5 \% \mathrm{III}$; thus, $87.5 \%$ of cases were stages I and II. The distal femoral growth plate was open at the time of surgery in $95 \%$ of cases.

The postoperative average follow up was 14.8 months (range 8-46 months).

The clinical and radiological evaluation of patients (Fig. 4) was performed by the Hughston score [14] (Tables 1 and 2).

This is a retrospective descriptive study. The statistical analysis has appealed, for quantitative variables, to nonparametric tests of Spearman, to search for correlations, analysis of variance (ANOVA) by ranks of the KruskalWallis test, and for comparison between groups. For qualitative variables, according to the effectiveness, Fisher's test or the Chi test were used. The significance level chosen was 0.05 .

\section{Surgical technique}

Transchondral drilling was described by Smillie in 1957 [15] and was performed, at that time, by open surgery. Currently, this technique is almost exclusively carried out with arthroscopy. So, after a conventional installation for knee arthroscopy, the diseased area is identified. This identification is made on the gross appearance of articular cartilage, gray or yellowish, with a frosted consistency, and abnormal to palpation due to its softening. In case of doubt, an intraoperative fluoroscopic tracking can help. Multiple perforations (5-10) using a fine 1.2-1.5-mm diameter $\mathrm{K}$ wire are made through the articular cartilage, opposite to the lesion of the subchondral bone and passing beyond the zone of sclerosis that circumscribes the lesion. After the drilling, one must observe bleeding from the healthy underlying bone through the puncture holes [16].

Postoperatively, non-weight-bearing for 1 month using two crutches with free mobilization of the knee has been proposed. Discontinuation of sport was the rule. Follow up involves clinical and radiographic monitoring. The resumption of sports activities was allowed 6 months after surgery.

\section{Results}

No complications were encountered during the perioperative period. The Hughston Clinic score was 0 in 2.5\%, 3 in $25 \%$, and 4 in $72.5 \%$; thus, giving $97.5 \%$ of good results (score 3 or 4 ). The clinical score of 0 corresponds to a skeletally mature patient.

The Hughston radiographic score was 2 in 5\%, 3 in $35 \%$, and 4 in $60 \%$; thus, giving $95 \%$ of good results (score 3 or 4) (Fig. 5). The radiological score of 2 was found in two skeletally mature patients. A significant correlation $(P<0.001)$ was found between the radiological and clinical scores of Hughston.

The closed nature of the growth plate at the time of surgery has a significant deleterious effect $(P<0.001)$ on the clinical and radiographic scores of Hughston.

On the contrary, we have not found any influence on the results of clinical and radiological Hughston scores of the lesion's volume, its radiological stage, or its location following the Cahill and Berg or Harding classification.

\section{Discussion}

The primary goal of the treatment of osteochondritis is to promote the consolidation of the subchondral bone, the preservation of cartilage, and to prevent osteoarthritis.

The 'immature' knee, whose physis is still open, has a high potential for cure [2], therefore, conservative treatment should always be the first-line choice in stable juvenile osteochondritis, knowing that about $50 \%$ of lesions develop in a positive way in a period of 10-18 months $[3,17]$. 

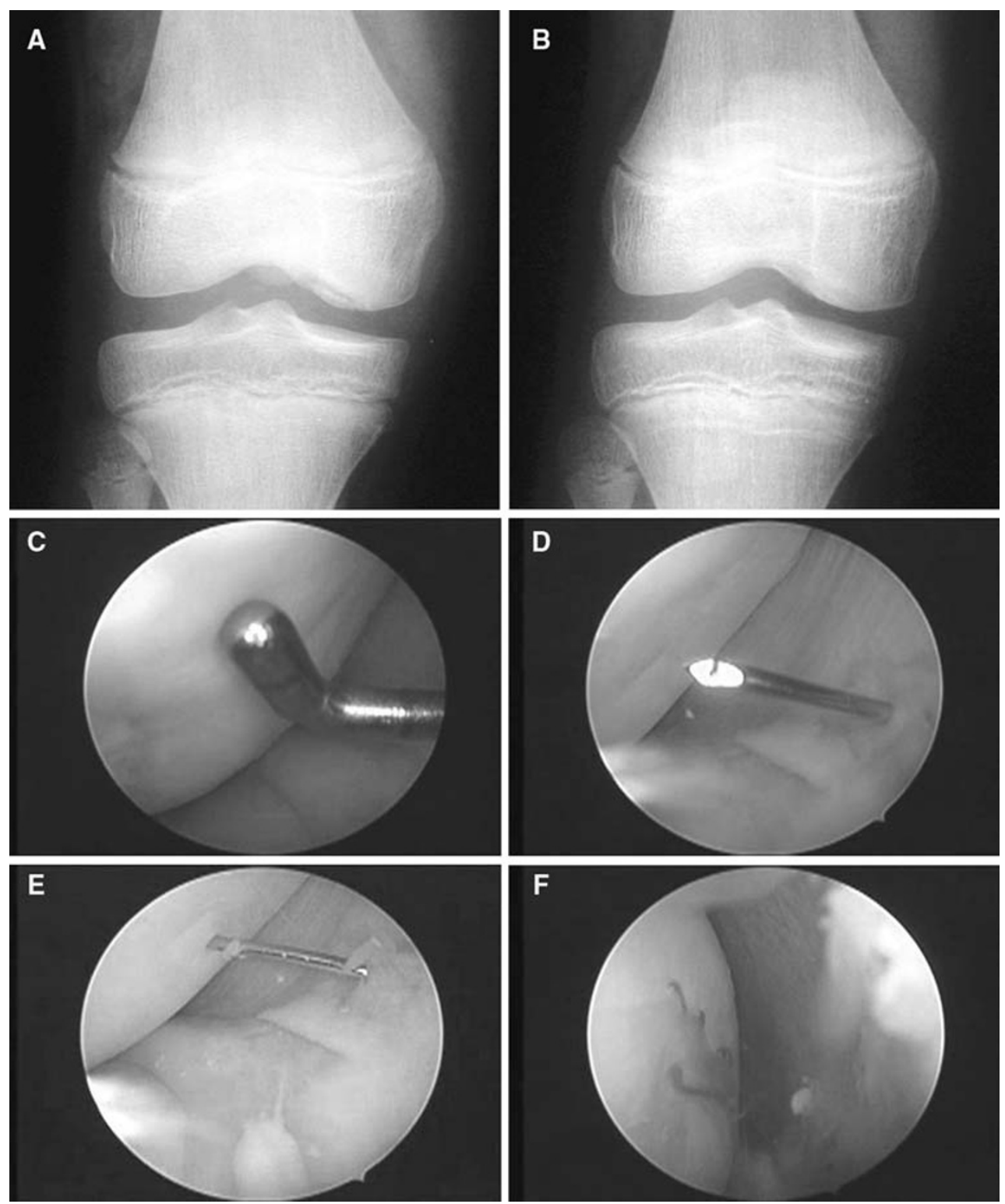

Fig. 5 a Grade II b Bedouelle OCD. b Radiograph 6 months later with a Hughston radiological score of 4. c Arthroscopic views for the same patient. Localization of the OCD region. d, e Transchondral drilling with a 1.2-mm K-wire. $\mathbf{f}$ Bleeding from the drilling holes

All patients in our series have maintained a conservative treatment by restriction of sports activities for an average of 6 months, and the use of surgical treatment was offered to one of the following criteria: instability or fragments sequestration, persistence of symptoms in a compliant patient, and the imminent closure of the physis. These indications were similar to those found in the literature [18-20].

For many authors, multiple transchondral drilling was the preferred treatment of juvenile osteochondritis condylar after failure of conservative treatment. Guhl [18] showed in their study that, among the 15 patients, aged 11-18 years, operated by multiple transchondral drilling, 13 had excellent and good results (86.7\%). Cepero et al. [19] showed excellent and good clinical and radiological results in $98 \%$ of patients operated on for arthroscopic drilling. Aglietti et al. [20] showed a normalization of radiological images in $87.5 \%$ of patients treated by drilling and all patients were clinically asymptomatic at 4 years of decline. Bradley and Dandy [21] have performed this technique and noted a radiological and clinical cure in $91 \%$ of patients after 2 years of decline. Anderson et al. [2] noted good results in $90 \%$ of patients with condylar juvenile osteochondritis. Transarticular drilling was conducted by Ganley et al. [22] in 49 patients aged under 18 years. The drilling was effective in $83 \%$ of immature knees against $75 \%$ of adolescents with a closed growth plate. Kocher et al. [23] studied the functional and radiological results of this technique in 23 patients with 30 lesions of osteochondritis for a 
mean of 3.9 years and found clinical and radiological healing in all patients. Louisia and Beaufils [24] have shown good clinical and radiological results in $70.6 \%$ of juvenile osteochondritis against $50 \%$ in adult osteochondritis.

In our series, all patients were operated by multiple arthroscopic transchondral drilling with good clinical and radiological results in 97.5 and $95 \%$ of cases, respectively. From a radiological point of view, the two patients who scored 2 on the Hughston scale were skeletally mature at the time of the surgery.

\section{Conclusion}

All patients with osteochondritis dissecans (OCD) of the femoral condyles with an open growth plate had good postoperative clinical and radiological outcomes, therefore, confirming the validity and effectiveness of multiple transchondral drilling in the treatment of juvenile OCD.

\section{References}

1. König F (1887) Ueber freie Körper in den Gelenken. Dtsch Z Chir 27:90-109

2. Anderson AF, Richards DB, Pagnani MJ, Hovis WD (1997) Antegrade drilling for osteochondritis dissecans of the knee. Arthroscopy 13(3):319-324

3. Cahill BR (1995) Osteochondritis dissecans of the knee: treatment of juvenile and adult forms. J Am Acad Orthop Surg 3:237247

4. Clanton TO, DeLee JC (1982) Osteochondritis dissecans. History, pathophysiology and current treatment concepts. Clin Orthop Relat Res 167:50-64

5. Glancy GL (1999) Juvenile osteochondritis dissecans. Am J Knee Surg 12:120-124

6. Pappas AM (1981) Osteochondrosis dissecans. Clin Orthop Relat Res 158:59-69

7. Murray JRD, Chitnavis J, Dixon P, Hogan NA, Parker G, Parish EN et al (2007) Osteochondritis dissecans of the knee; long-term clinical outcome following arthroscopic debridement. Knee 14:94-98

8. Kocher MS, Tucker R, Ganley TJ, Flynn JM (2006) Management of osteochondritis dissecans of the knee: current concepts review. Am J Sports Med 34(7):1181-1191
9. Mubarak SJ, Carroll NC (1979) Familial osteochondritis dissecans of the knee. Clin Orthop Relat Res 140:131-136

10. Hefti F, Beguiristain J, Krauspe R, Möller-Madsen B, Riccio V, Tschauner C et al (1999) Osteochondritis dissecans: a multicenter study of the European Pediatric Orthopedic Society. J Pediatr Orthop B 8:231-245

11. Harding WG 3rd (1977) Diagnosis of ostechondritis dissecans of the femoral condyles: the value of the lateral X-ray view. Clin Orthop Relat Res 123:25-26

12. Cahill BR, Berg BC (1983) 99m-Technetium phosphate compound joint scintigraphy in the management of juvenile osteochondritis dissecans of the femoral condyles. Am J Sports Med 11:329-335

13. Bedouelle J (1988) L'ostéochondrite disséquante des condyles fémoraux chez l'enfant et l'adolescent. In: Cahiers d'enseignement de la SOFCOT. Expansion Scientifique Française, pp 61-93

14. Hughston JC, Hergenroeder PT, Courtenay BG (1984) Osteochondritis dissecans of the femoral condyles. J Bone Joint Surg Am 66:1340-1348

15. Smillie IS (1957) Treatment of osteochondritis dissecans. J Bone Joint Surg Br 39:248-260

16. Lefort G, Moyen B, Beaufils P, De Billy B, Breda R, Cadilhac C et al (2006) L'ostéochondrite disséquante des condyles fémoraux: analyse de 892 cas. Rev Chir Orthop Traumatol 92(S5):97-141

17. Cahill BR, Phillips MR, Navarro R (1989) The results of conservative management of juvenile osteochondritis dissecans using joint scintigraphy. A prospective study. Am J Sports Med 17:601-606

18. Guhl JF (1982) Arthroscopic treatment of osteochondritis dissecans. Clin Orthop Relat Res 167:65-74

19. Cepero S, Ullot R, Sastre S (2005) Osteochondritis of the femoral condyles in children and adolescents: our experience over the last 28 years. J Pediatr Orthop B 14:24-29

20. Aglietti P, Buzzi R, Bassi PB, Fioriti M (1994) Arthroscopic drilling in juvenile osteochondritis dissecans of the medial femoral condyle. Arthroscopy 10:286-291

21. Bradley J, Dandy DJ (1989) Results of drilling osteochondritis dissecans before skeletal maturity. J Bone Joint Surg Br 71:642644

22. Ganley TJ, Amro RR, Gregg JR, Halpern KV (2002) Antegrade drilling for osteochondritis dissecans of the knee. Pediatric Orthopaedic Society of North America

23. Kocher MS, Micheli LJ, Yaniv M, Zurakowski D, Ames A, Adrignolo AA (2001) Functional and radiographic outcome of juvenile osteochondritis dissecans of the knee treated with transarticular arthroscopic drilling. Am J Sports Med 29:562-566

24. Louisia S, Beaufils P (1997) Perforations transcartilagineuses dans le traitement de l'ostéochondrite disséquante du condyle fémoral interne, vol 7. Sauramps Médical, Montpellier 